\title{
Prediksi Tinggi Gelombang Laut di Perairan Laut Sulawesi Utara dengan Menggunakan Model Vector Autoregressive (VAR)
}

\author{
Deastic Sumihi ${ }^{1}$, John S. Kekenusa ${ }^{2}$, Nelson Nainggolan ${ }^{3 *}$ \\ 1,2,3 Program Studi Matematika, Fakultas Matematika dan Ilmu Pengetahuan Alam, \\ Universitas Sam Ratulangi Manado \\ *corresponding author email : $\underline{\text { n-nelson@unsrat.ac.id }}$
}

\begin{abstract}
Abstrak
Telah dilakukan penelitian tentang tinggi gelombang laut di perairan laut Sulawesi Utara yang bertujuan untuk menerapkan model Vector Autoregressive (VAR) dalam memprediksi tinggi gelombang laut di wilayah perairan Bitung, perairan Manado, dan perairan Tahuna. Model VAR merupakan salah satu model time series yang menghendaki pemodelan secara simultan dengan beberapa peubah. Data yang digunakan dalam penelitian ini adalah data rata-rata harian tinggi gelombang laut di wilayah perairan Bitung, wilayah perairan Manado, dan wilayah perairan Tahuna yang diperoleh dari Badan Meteorologi, Klimatologi, dan Geofisika Maritim Bitung pada periode Januari 2015 sampai Desember 2016. Hasil penelitian menunjukkan bahwa model yang sesuai untuk memprediksi tinggi gelombang laut yaitu model VAR(3) dimana model ini cukup baik untuk digunakan dalam memprediksi tinggi gelombang laut wilayah Bitung, Manado, dan Tahuna pada periode 5 hari yakni tanggal 01 Januari 2017 sampai 05 Januari 2017, wilayah Bitung memiliki rata-rata tinggi gelombang mencapai 1,6 - 1,7 Meter, untuk tinggi gelombang laut wilayah Manado mencapai 1,3 - 1,5 Meter, dan wilayah Tahuna mencapai tinggi gelombang sebesar 1,8 - 2,1 Meter.
\end{abstract}

Kata Kunci : Model Vector Autoregressive (VAR), Tinggi Gelombang Laut, Sulawesi Utara

\section{Prediction of Sea Waves Height in North Sulawesi Sea Using Vector Autoregressive Model (VAR)}

\begin{abstract}
There has been a study of sea wave height in sea ocean being applied for Vector Autoregressive model (VAR) model in the prediction of sea wave height in Bitung sea location, Manado sea, and Tahuna sea. VAR model is one of the time series models that require simultaneous modeling with several variables. The data used in this study is the average daily data of sea wave height in the location of Bitung sea, Manado sea, and Tahuna sea obtained from the Meteorology, Climatology, and Geophysics Agency Bitung from January 2015 to December 2016. The results show that the model is suitable for predicting the sea wave height of the VAR model (3) where this model is good enough to be used in predicting the wave height of the Bitung, Manado, and Tahuna regions in the 5-day period from 01 January 2017 to 05 January 2017, Bitung region has a high average wave at 1.6 - 1.7 meters, for Manado the wave height reaches 1.3 - 1.5 meters, and the Tahuna region reaches wave height of $1.8-2.1$ meters.
\end{abstract}

Keywords : Vector Autoregressive Model (VAR), High Wave of the Sea, North Sulawesi

\section{Pendahuluan}

Provinsi Sulawesi utara secara geografis berada di ujung kepulauan Nusa Utara yang berperan sebagai pembatas Negara Indonesia dan Negara Filipina. Salah satu sektor maritim yang penting adalah kegiatan transportasi laut yang berupa pelayaran. Masyarakat dalam melaksanakan kegiatan pelayaran memerlukan informasi cuaca harian seperti tinggi gelombang dan angin kencang yang terjadi ditengah laut melalui laporan yang dikeluarkan Badan Meteorologi, Klimatologi, dan Geofisika (BMKG). Gelombang laut dapat dibangkitkan oleh angin, sistem badai, gempa bumi, dan gaya tarik bulan dan matahari. Peramalan gelombang berdasarkan data angin sebagai pembangkit utama gelombang dan daerah pembentukan gelombang (feth) [1]. Gelombang laut adalah bentuk permukaan laut yang berupa punggung atau puncak gelombang dan palung atau lembah gelombang 
oleh gerak ayun (oscillatory movement) akibat tiupan angin, erupsi gunung api, pelongsoran dasar laut, atau lalu lintas kapal [2]. Gelombang laut memiliki dimensi yaitu periode gelombang, panjang gelombang, tinggi gelombang, dan cepat rambat gelombang.

Model Time Series dapat menganalisis data stasioner dan non-stasioner, juga data musiman atau non-musiman. Beberapa model yang berbasiskan Time Series antara lain pemodelan ARIMA yang hanya menggunakan satu peubah (univariat). Pemodelan ARIMA ini telah dilakukan sebelumnya[3] dengan judul "Pemodelan ARIMA Dalam Prediksi Penumpang Pesawat Terbang Pada Bandara Internasional Sam Ratulangi Manado". Sedangkan untuk pemodelan secara simultan dengan beberapa peubah, dapat menggunakan model VARIMA. Salah satu model multivariat time series adalah model Vector Autoregressive (VAR) dimana Model VAR merupakan salah satu analisis time series multivariat yang berguna untuk melihat keterkaitan hubungan antara variabel. Sehingga pada penelitian ini dilakukan analisis time series dengan beberapa peubah menggunakan model Vector Autoregressive (VAR) dan menggunakan data tinggi gelombang laut pada tiga wilayah perairan laut Sulawesi Utara.

\section{Model Time Series}

Model Time Series dikenalkan oleh George E. P. Box dan Gwilym M. Jenkins pada tahun 1970 melalui bukunya Time Series Analysis : forecasting and control. Analisis Time Series merupakan metode peramalan kuantitatif untuk menentukan pola data pada masa lampau yang dikumpulkan berdasarkan urutan waktu, yang disebut data Time Series. Langkah penting dalam memilih suatu metode runtun waktu (Time Series) yang tepat adalah dengan mempertimbangkan jenis pola data, sehingga metode yang paling tepat adalah dengan pola data tersebut data diuji [4].

Prediksi adalah proses memperkirakan secara sistematis tentang sesuatu yang mungkin terjadi di masa depan berdasarkan informasi masa lalu dan sekarang yang dimiliki, agar kesalahannya dapat diperkecil. Prediksi tidak harus memberikan jawaban secara pasti suatu kejadian yang akan terjadi, melainkan berusaha untuk mencari jawaban sedekat mungkin yang akan terjadi [5].

Stasioneritas berarti bahwa tidak terdapat perubahan yang drastis pada data. Fluktuasi data berada di sekitar suatu nilai rata-rata yang konstan, tidak tergantung pada waktu dan varians dari fluktuasi tersebut [4]. Untuk mengatasi data deret waktu yang tidak stasioner dalam rataratanya, dapat dilakukan proses pembedaan (differencing) terhadap deret data asli. Metode ini dilakukan dengan cara mengurangi nilai data pada suatu periode dengan nilai data periode sebelumnya yang dapat dirumuskan sebagai berikut :

$$
W_{t}=Z_{t}-Z_{t-1}
$$

Autokorelasi adalah korelasi atau hubungan antara satu variabel satu atau lebih periode sebelumnya dengan dirinya sendiri. Koefisien autokorelasi untuk lag-k dari data runtun waktu dinyatakan sebagai berikut [4]:

$$
r_{k}=\rho_{k}=\frac{\sum_{t=1}^{n-k}\left(Z_{t}-\bar{z}_{t}\right)\left(Z_{t+k}-\bar{Z}_{t}\right)}{\sum_{t=1}^{n}\left(Z_{t}-\bar{Z}_{t}\right)^{2}}
$$

Autokorelasi parsial digunakan untuk mengukur tingkat keeratan antara $\mathrm{Zt}$ dan Zt-k apabila pengaruh dari lag waktu (time lag) $1,2,3, \ldots, \mathrm{k}-1$ dianggap terpisah. Koefisien autokorelasi parsial orde $m$ didefinisikan sebagai koefisien autoregresif terakhir dari model AR (m). Rumus fungsi autokorelasi parsial ditulis dengan [6]:

$$
\phi_{k+1, k+1}=\frac{\rho_{k+1}-\sum_{j=1}^{k-1} \phi_{k j} \rho_{k+1-j}}{1-\sum_{j=1}^{k-1} \phi_{k j} \rho_{j}} .
$$

Misalkan $\boldsymbol{Z}_{t}$ adalah multivariat time series stasioner lemah berdimensi $m$. Maka matriks kovariansi dari $\boldsymbol{Z}_{t}$ lag- $k$ adalah

$$
\Gamma(k)=\operatorname{Cov}\left(\boldsymbol{Z}_{t}, \boldsymbol{Z}_{t+k}\right)=E\left\{\left(\boldsymbol{Z}_{t}-\boldsymbol{\mu}\right)\left(\boldsymbol{Z}_{t+k}-\boldsymbol{\mu}\right)^{\prime}\right\}
$$




$$
\begin{gathered}
\left.\Gamma(k)=E\left[\begin{array}{c}
Z_{1, t}-\mu_{1} \\
Z_{2, t}-\mu_{2} \\
\vdots \\
\cdot \\
Z_{m, t}-\mu_{m}
\end{array}\right]\left[\left(Z_{1, t}-\mu_{1}\right)\left(Z_{2, t}-\mu_{2}\right) \ldots . . Z_{m, t}-\mu_{m}\right)^{\prime}\right] \\
=\left[\begin{array}{ccc}
\gamma_{11}(k) & \gamma_{12}(k) \ldots & \gamma_{1 m}(k) \\
\gamma_{21}(k) & \gamma_{22}(k) \ldots & \gamma_{2 m}(k) \\
\vdots & & \vdots \\
\gamma_{m 1}(k) & \gamma_{m 2}(k) \ldots & \gamma_{m m}(k)
\end{array}\right]
\end{gathered}
$$

dengan :

$$
\begin{aligned}
& \gamma_{i j}(k)=E\left(Z_{i, t}-\mu_{i}\right)\left(Z_{j, t+k}-\mu_{j}\right) \\
& \quad=E\left(Z_{i, t-k}-\mu_{i}\right)\left(Z_{j, t}-\mu_{j}\right) \\
& k=0, \pm 1, \pm 2, \ldots \ldots \ldots, \text { adalah lag }- \text { waktu, } \\
& m=\text { dimensi dari } \boldsymbol{Z}_{t} \\
& i=1,2,3, \ldots . ., m \text { dan } j=1,2,3, \ldots \ldots m .
\end{aligned}
$$

$\Gamma(k)$ dinamakan fungsi matriks kovariansi untuk proses vektor $\boldsymbol{Z}_{t}$, sedangkan $\gamma_{i j}(k)$ dinamakan fungsi matriks cross-kovariansi antara $Z_{i, t}$ dan $Z_{j, t+k}$ [7].

Dari definisi fungsi matriks korelasi $\boldsymbol{\rho}(k)$, maka elemen-elemen dari matriks korelasi ini $\rho_{i j}(k)$ dapat dituliskan sebagai:

$$
\rho_{\mathrm{ij}}(\mathrm{k})=\frac{\gamma_{\mathrm{ij}}(\mathrm{k})}{\left[\gamma_{\mathrm{ii}}(0) \gamma_{\mathrm{jj}}(0)\right]^{1 / 2}}=\frac{\operatorname{Cov}\left(\mathrm{Z}_{\mathrm{i}, \mathrm{t}}, \mathrm{Z}_{\mathrm{j}, \mathrm{t}+\mathrm{k}}\right)}{\left(\operatorname{Var}\left(\mathrm{Z}_{\mathrm{i}, \mathrm{t}}\right)\left(\operatorname{Var}\left(\mathrm{Z}_{\mathrm{j}, \mathrm{t}}\right)\right)^{1 / 2}\right.}
$$

dimana :

$\rho_{i j}(k)$ adalah fungsi cross-korelasi antara $Z_{i, t}$ dan $Z_{j, t+k}$.

\section{Model Vector Autoregressive (VAR)}

Vector Autoregressive (VAR) dikemukakan pertama kali oleh Sims (1980). Metode Vector Autoregressive (VAR) adalah suatu pendekatan peramalan kuantitatif yang biasanya diterapkan pada data Multivariate time series. Model vektor yang paling sederhana adalah model Vector Autoregressive (VAR) [7]. Misalkan $\boldsymbol{Z}_{t}$ adalah vektor time series stasioner lemah berdimensi $m$. Model VAR Orde-1, VAR(1), adalah berbentuk:

$$
\left(I-\Phi_{1} B\right) \boldsymbol{Z}_{t}=\varepsilon_{t} \text { atau } \boldsymbol{Z}_{t}=\Phi_{1} \boldsymbol{Z}_{t-1}+\varepsilon_{t}
$$

dengan $\boldsymbol{\varepsilon}_{t} \stackrel{\text { i.i.d }}{\sim} N(0, \Sigma)$, dimana $\Sigma$ matriks $m \times m$, simetri, definit positif. Untuk proses white noise diasumsikan: $\Sigma=\sigma^{2} \boldsymbol{I}_{m}$. Secara khusus, untuk $m=2$, maka VAR(1) dapat dituliskan sebagai :

$$
\begin{gathered}
Z_{1, t}=\phi_{11} Z_{1, t-1}+\phi_{12} Z_{2, t-1}+\varepsilon_{1, t} \\
Z_{2, t}=\phi_{21} Z_{1, t-1}+\phi_{22} Z_{2, t-1}+\varepsilon_{2, t} \\
\left(\begin{array}{l}
Z_{1, t} \\
Z_{2, t}
\end{array}\right)-\left(\begin{array}{ll}
\varphi_{11} & \varphi_{12} \\
\varphi_{21} & \varphi_{22}
\end{array}\right)\left(\begin{array}{l}
Z_{1, t-1} \\
Z_{2, t-1}
\end{array}\right)=\left(\begin{array}{l}
\varepsilon_{1, t} \\
\varepsilon_{2, t}
\end{array}\right)
\end{gathered}
$$

proses VAR(1) stasioner apabila akar-akar dari persamaan $\left|I-\Phi_{1} B\right|=0$ terletak di luar lingkaran satuan. Misalkan $\lambda=B^{-1}$, maka $\left|\boldsymbol{I}-\boldsymbol{\Phi}_{\mathbf{1}} \boldsymbol{B}\right|=0 \Leftrightarrow\left|\lambda \boldsymbol{I}-\boldsymbol{\Phi}_{\mathbf{1}}\right|=0$ 
Dalam proses pembentukan model tahap identifikasi meliputi identifikasi plot deret waktu, fungsi autokorelasi (ACF) dan fungsi autokorelasi parsial (PACF). Selain itu penentuan orde juga mempertimbangkan nilai AIC (Akaike's Information Criterion) yang paling minimum. Model semakin sesuai jika memiliki nilai AIC terendah. AIC adalah bentuk akhir dari fungsi loglikelihood [7] yaitu:

$$
\mathrm{AIC}=-2 \log (\mathrm{L})+2 m
$$

dengan $\mathrm{L}$ adalah maksimum likelihood dan $\mathrm{m}$ adalah banyaknya parameter yang akan ditaksir dalam AR, model MA dan koefisien regresi.

Dalam data terdapat sebagian data yang diketahui dapat digunakan untuk memprediksi sisa data berikutnya sehingga dapat dilakukan perhitungan ketepatan prediksi secara lebih baik. Penaksiran parameter model VAR(p) dapat dilakukan dengan menggunakan metode Kuadrat Terkecil (Ordinary Least Squares).

Uji diagnostik perlu dilakukan untuk menguji bahwa model tersebut cukup memadai dan menentukan model mana yang terbaik untuk peramalan [4]. Model dikatakan memadai jika asumsi dari error memenuhi proses white noise dan berdistribusi normal. Apabila dijumpai penyimpangan yang cukup serius maka harus dirumuskan kembali model yang baru, selanjutnya di estimasi dan dilakukan pemeriksaan kembali.

\section{Metodologi Penelitian}

Data yang digunakan dalam penelitian ini merupakan data sekunder yang diperoleh dari Badan Meteorologi, Klimatologi, dan Geofisika Maritim Bitung berupa data rata-rata harian tinggi gelombang laut di wilayah perairan Bitung, perairan Manado, dan perairan Tahuna pada periode Januari 2015 sampai Desember 2016. Langkah-langkah penerapan model VAR sebagai berikut:

Pengumpulan Data, Plot Data, Pemeriksaan Kestasioneran Data, Identifikasi Model, Penaksiran Parameter VAR, Penentuan Persamaan VAR, Verifikasi Model, Validasi Model, Prediksi.

\section{Hasil dan Pembahasan}

Pada analisis data untuk melihat apakah data sudah stasioner atau tidak, maka dilakukan Uji stasioneritas menggunakan uji akar-akar unit (unit root test) dengan metode Augmented Dickey Fuller Test (ADF-Test). Variabel dikatakan stasioner (tidak mempunyai unit root) apabila nilai probabilitas (Prob*) berada di bawah 0,05. Berdasarkan hasil uji ADF menunjukkan bahwa ketiga variabel sudah stasioner pada tingkat level, Sehingga dapat dikatakan data sudah bersifat stasioner karena nilai statistic Uji dari Augmented Dickey Fuller Test (ADF-Test) lebih kecil daripada nilai Kritik dari $1 \%, 5 \%$ dan $10 \%$ serta nilai probabilitasnya berada di bawah 0,05 .

Kemudian berdasarkan hasil plot correlogram fungsi autokorelasi (ACF) dan fungsi autokorelasi parsial (PACF) dari data rata-rata harian tinggi gelombang laut di wilayah perairan Bitung, Manado, dan Tahuna sudah bersifat stasioner.

Setelah data sudah stasioner langkah selanjutnya adalah identifikasi model. Pada tahap ini dilakukan pemilihan kriteria untuk menentukan orde VAR yaitu dengan melihat nilai AIC (Akaike's Information Criterion) dan SIC (Schwarz Information Criterion) terkecil pada beberapa orde model. Berdasarkan hasil perhitungan dengan bantuan software Eviews 7, diperoleh nilai AIC sebesar 3,732907 dan nilai SIC sebesar -3,597072. Hasil menunjukkan nilai AIC lebih kecil dari nilai SIC dari berbagai lag yang diajukan yaitu berada pada lag ke-3 yang berarti bahwa lag optimal ialah lag ke-3. Sehingga dapat diduga pada tahap identifikasi diperoleh model sementara yang sesuai adalah VAR orde-3 atau VAR(3).

Selanjutnya penaksiran parameter yang dilakukan dengan metode kuadrat terkecil (Ordinary least square) menggunakan software Eviews 7, dibuat persamaan dari model VAR Orde3 atau $\operatorname{VAR}(3)$ menjadi:

$\hat{Z}_{1, t}=0,125+1,071 Z_{1, t-1}-0,077 Z_{2, t-1}+0,200 Z_{3, t-1}-0,191 Z_{1, t-2}-0,018 Z_{2, t-2}-$

$0,216 Z_{3, t-2}-0,026 Z_{1, t-3}+0,034 Z_{2, t-3}+0,106 Z_{3, t-3} \ldots \ldots \ldots \ldots \ldots \ldots \ldots \ldots \ldots \ldots \ldots \ldots . .(5)$ 


$$
\begin{aligned}
\hat{Z}_{2, t}= & 0,065+0,283 Z_{1, t-1}+0,639 Z_{2, t-1}+0,261 Z_{3, t-1}-0,133 Z_{1, t-2}-0,071 Z_{2, t-2}- \\
& 0,218 Z_{3, t-2}-0,015 Z_{1, t-3}+0,034 Z_{2, t-3}+0,083 Z_{3, t-3} \ldots \ldots \ldots \ldots \ldots \ldots \ldots \ldots \ldots \ldots \ldots \ldots \ldots \ldots \ldots \ldots \ldots \ldots \ldots \\
\hat{Z}_{3, t}= & 0,081+0,108 Z_{1, t-1}+0,011 Z_{2, t-1}+1,024 Z_{3, t-1}-0,031 Z_{1, t-2}+0,044 Z_{2, t-2}- \\
& 0,355 Z_{3, t-2}-0,036 Z_{1, t-3}+0,028 Z_{2, t-2}+0,166 Z_{3, t-3} \ldots \ldots \ldots \ldots \ldots \ldots
\end{aligned}
$$

dimana :

$$
\begin{aligned}
& Z_{1, t}=\text { tinggi gelombang laut Bitung pada waktu } \mathrm{t} \\
& Z_{2, t}=\text { tinggi gelombang laut Manado pada waktu } \mathrm{t} \\
& Z_{3, t}=\text { tinggi gelombang laut Tahuna pada waktu } \mathrm{t}
\end{aligned}
$$

Dalam bentuk matriks :

$$
\begin{aligned}
{\left[\begin{array}{l}
\hat{Z}_{1, t} \\
\hat{Z}_{2, t} \\
\hat{Z}_{3, t}
\end{array}\right]=} & {\left[\begin{array}{l}
0,125 \\
0,065 \\
0,081
\end{array}\right]+\left[\begin{array}{ccc}
1,071 & -0,077 & 0,200 \\
0,283 & 0,639 & 0,261 \\
0,108 & 0,011 & 1,024
\end{array}\right]\left[\begin{array}{l}
Z_{1, t-1} \\
Z_{2, t-1} \\
Z_{3, t-1}
\end{array}\right]+} \\
& {\left[\begin{array}{rrr}
-0,191 & -0,018 & -0,216 \\
-0,133 & -0,071 & -0,218 \\
-0,031 & 0,044 & 0,355
\end{array}\right]\left[\begin{array}{l}
Z_{1, t-2} \\
Z_{2, t-2} \\
Z_{3, t-2}
\end{array}\right]+\left[\begin{array}{lll}
-0,026 & 0,034 & 0,083 \\
-0,015 & 0,034 & 0,083 \\
-0,036 & 0,028 & 0,166
\end{array}\right]\left[\begin{array}{l}
Z_{1, t-3} \\
Z_{2, t-3} \\
Z_{3, t-3}
\end{array}\right] \ldots \ldots \ldots . .(8) }
\end{aligned}
$$

Selanjutnya dilakukan uji verifikasi model. Uji ini dilakukan untuk mengetahui apakah model telah merepresentasikan data dengan baik. Uji kelayakan ini dilakukan dengan menggunakan correlogram residual dan plot dari error. Adapun hipotesis dalam pengujian ini adalah sebagai berikut.

Hipotesis :

H0 : Data memenuhi syarat cukup (residual memenuhi syarat white noise)

H1 : Data belum memenuhi syarat cukup (residual belum memenuhi syarat white noise)

Dengan $\alpha$ sebesar 5\%

Jika P-value $<\alpha=5 \%$ maka menolak H0 yang dimana berarti data belum memenuhi syarat cukup (residual belum memenuhi syarat white noise).

Berdasarkan correlogram residual dari ketiga model, terlihat bahwa nilai probabilitas dari masing-masing lag yang diajukkan lebih besar dari alpha 0,05 dengan kata lain Ho diterima yang berarti data sudah memenuhi syarat cukup (residual memenuhi syarat white noise).

Berdasarkan plot residual dari masing-masing variabel menunjukkan bahwa error tidak membentuk suatu pola tertentu dan terdistribusi disekitar nol. Sehingga dapat disimpulkan bahwa sifat interpendensi pada error (error tidak autokorelasi) telah terpenuhi. Dengan demikian, asumsi pada model VAR terpenuhi.

Dalam uji validasi model, dilakukan dengan membandingkan kondisi data dari ketiga wilayah tersebut untuk mengetahui kondisi data sebenarnya(aktual) dengan data prediksi. Validasi model VAR(3) dari bulan Januari 2015 sampai bulan Desember 2016. Dari hasil plot data, masingmasing wilayah tersebut terlihat dari hari pertama Januari 2015 sampai hari terakhir bulan Desember 2016 data aktual tidak berbeda jauh dengan hasil prediksi, terlihat keakuratan dari model prediksi setiap harinya saling tumpang tindi. Sehingga dapat dikatakan model VAR(3) bisa digunakan untuk memprediksi tinggi gelombang laut Bitung, Manado, dan Tahuna pada beberapa hari ke depan.

Hasil prediksi untuk rata-rata harian tinggi gelombang laut di wilayah Bitung, wilayah Manado dan wilayah Tahuna mulai dari periode 25 Desember 2016 sampai 05 Januari 2017 disajikan pada tabel 1. Hasil analisisnya yaitu pada tanggal 01 Januari 2017 ketiga wilayah tersebut mengalami kenaikan tinggi gelombang laut dimana gelombang laut wilayah Bitung mencapai tinggi gelombang sebesar 1,78 meter, wilayah Manado mencapai 1,53 meter dan di wilayah Tahuna mencapai 2,19 meter dimana pada periode 01 Januari 2017 sampai 05 Januari 2017 wilayah Tahuna adalah wilayah yang mempunyai gelombang laut tertinggi dibandingkan dengan wilayah Bitung dan wilayah Manado. Dan pada periode itu juga wilayah Manado adalah wilayah yang mempunyai tinggi gelombang laut terendah diantara wilayah Bitung dan Tahuna dengan ketinggian gelombang laut sebesar 1,34 meter. 
Tabel 1. Hasil prediksi rata-rata harian tinggi gelombang laut di wilayah Bitung,Manado, dan Tahuna pada periode 5 hari

\begin{tabular}{|c|c|c|c|c|c|c|}
\hline \multirow{2}{*}{ Periode } & \multicolumn{3}{|c|}{ Prediksi } & \multicolumn{3}{c|}{ Aktual } \\
\cline { 2 - 7 } & $\begin{array}{c}\text { Bitung } \\
(\mathrm{m})\end{array}$ & $\begin{array}{c}\text { Manado } \\
(\mathrm{m})\end{array}$ & $\begin{array}{c}\text { Tahuna } \\
(\mathrm{m})\end{array}$ & $\begin{array}{c}\text { Bitung } \\
(\mathrm{m})\end{array}$ & $\begin{array}{c}\text { Manado } \\
(\mathrm{m})\end{array}$ & $\begin{array}{c}\text { Tahuna } \\
(\mathrm{m})\end{array}$ \\
\hline 25 Desember 2016 & 1,80 & 1,49 & 1,94 & 1,70 & 1,52 & 1,86 \\
26 Desember 2016 & 1,60 & 1,40 & 1,79 & 1,52 & 1,28 & 1,50 \\
27 Desember 216 & 1,41 & 1,15 & 1,45 & 1,39 & 1,07 & 1,52 \\
28 Desember 2016 & 1,40 & 1,10 & 1,56 & 1,47 & 1,09 & 1,56 \\
29 Desember 2016 & 1,48 & 1,14 & 1,55 & 1,84 & 1,27 & 1,69 \\
30 Desember 2016 & 1,86 & 1,36 & 1,70 & 1,71 & 1,42 & 1,85 \\
31 Desember 2016 & 1,64 & 1,37 & 1,81 & 1,77 & 1,50 & 2,25 \\
01 Januari 2017 & 1,78 & 1,53 & 2,19 & - & - & - \\
02 Januari 2017 & 1,70 & 1,46 & 2,03 & - & - & - \\
03 Januari 2017 & 1,64 & 1,40 & 1,95 & - & - & - \\
04 Januari 2017 & 1,61 & 1,37 & 1,90 & - & - & - \\
05 Januari 2017 & 1,59 & 1,34 & 1,85 & - & - \\
\hline
\end{tabular}

Pada penelitian ini koefisien determinasi atau nilai $R^{2}$ (R-squared) digunakan untuk menentukan kebaikan model dalam memprediksi. Dengan kata lain, menggambarkan berapa persen model tersebut mampu menerangkan kondisi yang sebenarnya(aktual). nilai $R^{2}$ yang diperoleh dari masing-masing variabel yakni untuk wilayah Bitung sebesar 0,85154 atau 85,154\%; untuk wilayah Manado sebesar 0,870404 atau 87,040\% dan untuk wilayah Tahuna 0,840676 atau 84,067\%. Hal ini berarti model VAR cukup baik atau sesuai untuk memprediksi tinggi gelombang laut menggunakan ketiga variabel tersebut. Sedangkan sisanya sebesar 14,846\%; 12,96\%; dan 15,93\% dipengaruhi atau dijelaskan oleh variabel lain yang tidak dimasukkan dalam model penelitian ini.

\section{Kesimpulan}

1. Model time series untuk prediksi tinggi gelombang laut diperairan laut Sulawesi Utara khususnya wilayah Bitung, Manado dan Tahuna menggunakan data rata-rata harian tinggi gelombang laut periode Januari 2015 sampai dengan Desember 2016 diperoleh model VAR(3) yang dipilih dari nilai AIC terkecil.

2. Prediksi rata-rata harian tinggi gelombang laut di wilayah Bitung, Manado, dan Tahuna yakni tanggal 01 Januari 2017 sampai 05 Januari 2017 wilayah bitung memiliki rata-rata tinggi gelombang laut mencapai 1,6 - 1,7 meter , tinggi gelombang laut wilayah Manado sebesar 1,3 - 1,5 meter dan wilayah Tahuna mencapai tinggi gelombang signifikan sebesar 1,8 - 2,1 meter. Dengan nilai $\mathrm{R}^{\wedge} 2$ yang diperoleh dari masing-masing variabel yakni 0,85154 atau $85,154 \%$ untuk wilayah Bitung, 0,870404 atau 87,040\% untuk wilayah Manado dan 0,840676 atau $84,067 \%$ untuk wilayah Tahuna. Hal ini berarti model VAR sesuai untuk memprediksi tinggi gelombang laut di wilayah Bitung, Manado, dan Tahuna. 


\section{Daftar Pustaka}

[1] Zakaria, A. 2009. Bahan Ajar Teori Gelombang Amplitudo Kecil Dan Peramalan Gelombang. Jurusan Teknik Sipil, Fakultas Teknik, Universitas Lampung.

[2] Sunarto, 2003. Geomorfologi Pantai: Dinamika Pantai, Yogyakarta: Laboratorium Geomorfologi Terapan, Jurusan Geografi Fisik, Fakultas Geografi, Universitas Gadjah Mada.

[3] Salmon, H. A. S., N. Nainggolan, D. Hatidja. 2015. Pemodelan ARIMA Dalam Prediksi Penumpang Pesawat Terbang Pada Bandara Internasional Sam Ratulangi Manado. Journal de Cartesian. 4(1): 60-67.

[4] Makridakis, S., Wheelwright, S.C., \& McGee, V.E. 1999. Metode dan Aplikasi Peramalan Jilid 1 Edisi Kedua. Terjemahan Ir. Untung S. Andriyanto dan Ir. Abdul Basith. Erlangga, Jakarta.

[5] Lilipaly, G. S., D. Hatidja, J.S. Kekenusa. 2014. Prediksi Harga Saham PT. BRI, Tbk. Menggunakan Metode ARIMA (Autoregressive Integrated Moving Average). Jurnal Ilmiah Sains. 14(2): 61-67.

[6] Wei, W.W.S. 2006. Time Series Analysis:Univariate and Multivariat Methods. $2^{\text {nd }}$ Edition. New York: Addison Wesley Publishing Company, Inc.America.

[7] Nainggolan, N. 2009. Model Time Series Heteroskedastik.Unpad Press. Bandung. 